\title{
Longitudinal trends of future climate change and oil palm growth: empirical evidence for tropical Africa
}

\author{
R. Russell M. Paterson ${ }^{1,2}$ (D) \\ Received: 1 May 2020 / Accepted: 13 December 2020 / Published online: 6 January 2021 \\ (C) The Author(s), under exclusive licence to Springer-Verlag GmbH, DE part of Springer Nature 2021
}

\begin{abstract}
Palms are highly significant tropical plants. Oil palms produce palm oil, the basic commodity of a highly important industry. Climate change from greenhouse gasses is likely to decrease the ability of palms to survive, irrespective of them providing ecosystem services to communities. Little information about species survival in tropical regions under climate change is available and data on species migration under climate change is important. Palms are particularly significant in Africa: a palm oil industry already exists with Nigeria being the largest producer. Previous work using CLIMEX modelling indicated that Africa will have reduced suitable climate for oil palm in Africa. The current paper employs this modelling to assess how suitable climate for growing oil palm changed in Africa from current time to 2100. An increasing trend in suitable climate from west to east was observed indicating that refuges could be obtained along the African tropical belt. Most countries had reduced suitable climates but others had increased, with Uganda being particularly high. There may be a case for developing future oil palm plantations towards the east of Africa. The information may be usefully applied to other palms. However, it is crucial that any developments will fully adhere to environmental regulations. Future climate change will have severe consequences to oil palm cultivation but there may be scope for eastwards mitigation in Africa.
\end{abstract}

Keywords Elaeis guineensis $\cdot$ Global warming $\cdot$ Suitable climate $\cdot$ Longitude $\cdot$ Trend $\cdot$ Democratic Republic of Congo

\section{Introduction}

Palms are iconic plants (Cosiaux et al. 2018) which are highly significant to humans and biodiversity. Vast plantations of oil palm (Elaeis guineensis) exist, allowing a large global industry to develop by producing palm oil, with highly significant consequences to the general economy and environment (Paterson and Lima 2018). African palms are likely to be affected detrimentally by climate change from increased greenhouse gasses and may not survive, although there appears a low extinction risk in the immediate future. It is crucial

Responsible Editor: Philippe Garrigues

R. Russell M. Paterson

russell.paterson@deb.uminho.pt

1 CEB - Centre of Biological Engineering, Gualtar Campus, University of Minho, 4710-057 Braga, Portugal

2 Department of Plant Protection, Faculty of Agriculture, Universiti Putra Malaysia, 43400 UPM Serdang, Selangor D.E., Malaysia to understand the climate change threats to these plants (Cosiaux et al. 2018).

The effects of climate change are manifested by phenology and future climate warming may disrupt many ecosystems (Thackeray et al. 2010). Rosenzweig et al. (2008) indicated demographic changes in suitable climate for species growth from climate change. Bellard et al. (2012) pointed out weaknesses of models, in that not all relevant parameters are considered, but also indicated that climate scenarios depend on a wide range of socio-economic 'storylines'. Studies indicate high levels of ecological changes caused by climate change by employing scientific inference (Parmesan 2006). Extinction rates of species (Sinervo et al. 2010) will accelerate with the intensification of climate change (Urban 2015). The majority of studies extrapolate correlations between current climate and species distributions to novel conditions and temperature-sensitive species might extend their ranges to cool refuges (Wright et al. 2009).

Many climate change studies are limited in scope, including a lack of information on non-tropical species: They do not often consider (a) a wider range of factors (e.g. precipitation) apart from temperature, and (b) longitudinal change (Feeley 
et al. 2017). Focussing on only change to higher latitudes and temperature underestimates the effect of climate change. Poleward movements and upward shifts in species' climaterelated range are the most reported responses by far (Fei et al. 2017). Cho and Mccarl (2017) found that climate explained a longitudinal trend in favouring particular crops. Successional processes were more sensitive to changes in moisture availability than to temperature for trees in the USA, where a longitudinal effect was reported (Fei et al. 2017). Miller et al. (2017) determined that forest responses to climate change were apparent near the western range limit of white spruce in Alaska. Nevertheless, Sittaro et al. (2017) suggested tree species were predominantly limited in their capacity to track climate warming, supporting concerns that warming will impact negatively forest ecosystems.

There is a paucity of information on climate change in the tropics (Feeley et al. 2017; Ghini et al. 2011) and research efforts are weak in central Africa, where studies covering large areas are lacking and data on thermoregulatory behaviours do not exist for tropical lowland plants. The absence of tropical species from most global climate syntheses is especially dangerous because they are expected to have fundamentally different responses to climate change than temperate counterparts. Tropical plants should be a priority in global change research since there are no pools of plants living in a hotter climate that are available to replace declining species in tropical lowland, leading to tropical lowland biotic attrition with potentially negative consequences for ecosystem functioning (Lenoir and Svenning 2015; Feeley et al. 2017). On the other hand, the high levels of oil palm cultivation contribute to reduce ecosystem function (Dislich et al. 2017).

The absence of latitudinal temperature gradients within the tropics (Wright et al. 2009) eliminates poleward migrations as a survival mechanism for most equatorial species. It was further suggested that tropical forest species will be particularly sensitive to global warming. Temperature-sensitive species might extend their ranges to cool refuges, although distances to these refuges are the greatest for equatorial species and are particularly large for the Congo River Basins, West Africa, and the upper elevations of many tropical mountains. Tropical species are likely to be (a) particularly sensitive to global warming because they are adapted to limited geographic and seasonal variation in temperature, (b) living at or near the highest temperatures on Earth before global warming began and (c) isolated from cool refuges. The distance to the nearest cool refuge exceeds $1000 \mathrm{~km}$ for more than $20 \%$ of tropical species. In the Northern hemisphere, movements have been estimated at $1.69 \mathrm{~km}$ year $^{-1}$ to higher latitudes (Lenoir and Svenning 2015). A strong latitudinal temperature gradient averages $1{ }^{\circ} \mathrm{C}$ for each $145-\mathrm{km}$ change in latitude between the Tropics and Polar Regions but approaches zero between the Tropics of Cancer and Capricorn. However, only a few poleward range shifts have been reported for terrestrial plants, although a recent example is from (Lena et al. 2018) who indicated a possible expansion of an almond crop polewards.

Palms represent bedrock species in the tropics providing essential ecosystem services to rural people worldwide, although many palms are threatened by over-exploitation and habitat loss. African palm species will experience a decline in climatic suitability in $>70 \%$ of their current ranges by 2080 (Blach-Overgaard et al. 2015), reducing to ca. 35\% if migration to nearby climatically-suitable sites succeeds. However, this is difficult in latitudinal directions in the tropics because there are no temperature gradients in these directions (Wright et al. 2009). Furthermore, losses of important palm habitats such as tropical rain forests are steadily exacerbating the pressures on palm populations. Consequently, palms and their ecosystem functions and services will be highly sensitive to climate change. Oil palm cultivation itself involves deforestation (Dislich et al. 2017; Paterson and Lima 2018), and hence, the development of oil palm could threaten other palms. It is fundamental to comprehend how climate change will affect African palms given their socioeconomic and ecological importance. Blach-Overgaard et al. (2015 ) predicted climate suitability losses across almost all terrains where palms occur in Africa, especially in the Guineo-Congolian Floristic Region. However, most open-habitat palms were projected to lose climate suitability in coastal East Africa and West Africa. The oil palm, the subject of the present paper, falls into both categories and will be affected in all these regions: climate suitability increases were predicted for fewer species in smaller areas. A decline was projected in climate suitability in $70 \%$ of their current predicted ranges by 2080 for all palms. Many palms could potentially track suitable climate space by dispersing within 100-km distance of their current range margins: The highest gains in climate suitability were in westcentral Africa for palms overall and for rainforest palms, but in south-eastern Africa for open-habitat palms. In reality, these gains may not be met due to habitat fragmentation with novel anthropogenic habitats constituting dispersal barriers.

The awareness of climate change threatening crop production has increased (Lobell et al. 2006). Ramirez-cabral et al. (2017) indicated that large areas that are suitable for global maize cultivation will suffer from heat and dry stresses that may constrain production. Shabani et al. (2014) determined that future climate could favour plant pathogenic Fusarium oxysporum threatening more infection of crops. Paterson (2020) modelled increased mortality and disease of oil palm from climate change.

Oil palm (E. guineensis) originated in Africa, as the name indicates, as part of the tropical forest. Palm oil is used in numerous foods, cosmetics, pharmaceuticals, biodiesel and is employed in domestic cooking at very high volumes (Paterson et al. 2017). On the other hand, oil palm plantations have detrimental environmental consequences especially with respect to deforestation (Paterson and Lima 2018) and the oil 
and its production are associated with human health problems (Kadandale and Smith 2019), adding to the overall significance of oil palm.

Palm oil manufacturing began commercially in Malaysia in 1917 (Basiron 2007) and 85\% of palm oil is now produced by Malaysia and Indonesia (Ommelna et al. 2012). The rest of the world accounts for $14 \%$ of the world's supply and oil palm may be grown increasingly in other countries as suitable land becomes scarce and climate is unconducive to growth, in Malaysia and Indonesia. For example, there are only $3.0 \times$ $10^{5}$ ha remaining in Malaysia (Villela et al. 2014) and growing oil palm in Malaysia and Indonesia may become difficult as climate change progresses (Marlier et al. 2014). In addition, other nations will produce palm oil to boost their economies, forming potential competitors to Malaysia and Indonesia. Indeed, many countries have plans to increase the amount/ area of oil palm grown (Arrieta et al. 2007; Ohimain and Izah 2014; Paterson et al. 2015). There are significant industries in tropical Africa. Nigeria, Ghana, Ivory Coast, Cameroon, Sierra Leon, Benin, Angola and DRC are the main producers and in that order, although Cameroon and Ivory Coast are the only exporters of palm oil (Corley and Tinker 2015). Nigeria is the fourth highest manufacturer globally with an average yield of palm oil of $1.3 \times 10^{6}$ million tonnes and the country produced biodiesel at $6 \cdot 0 \times 10^{3} 1 /$ ha oil palm in 2007 (Abila 2010). African states could, in theory, increase their market share as land in Malaysia and Indonesia becomes less available (Paterson and Lima 2018).

Paterson et al. (2017) considered future changes to suitable climate for growing oil palm in a worldwide setting by using modelling techniques that employed temperature and moisture parameters such as soil moisture and wet stress. There was a large area of highly suitable climate in Africa, extending east from Sierra Leone to almost all of DRC. Many of the other countries in this zone have large areas of highly suitable climate and a large number of occurrences of E. guineensis plantations were recorded. The general trend was for a reduced level of suitable climate in 2050 and even greater reductions by 2100: reductions in highly suitable climate for Nigeria were projected to be to 1 from $69 \mathrm{~km}^{2}$ in 2100 . However, suitable climate increased with climate change in Madagascar. The projections indicate serious consequences to the PO industry generally, and that the climate will become unsuitable for growing oil palm at the same rate, or faster than, Malaysia and Indonesia. There was no attempt at an indepth study of trends within the African countries from the maps provided.

The current paper considers how suitable climate for the growth of oil palm changes across most of the relevant countries in Africa based on the information in Paterson et al. (2017). There is a paucity of information in the scientific literature on (a) climate effects in tropical countries, (b) other conditions apart from temperature and (c) longitudinal effects, which the current paper addresses.

\section{Material and methods}

The CLIMEX mechanistic niche model described in Paterson et al. (2017) provided scenarios of suitable climate for growing oil palm under climate change in Africa and was used to provide information from the maps for current time, 2050 and 2100 (Fig. 1). The only nations that are not in the tropics in Africa are Morocco and Tunisia in the north and Lesotho and Swaziland in the south. All the rest lie either entirely, or at least partly, within the tropics as defined by the latitudes of the Tropics of Cancer and Capricorn. Tropical Africa tends to have a hot or warm climate which is caused by the latitude and a tropical rain belt. However, this varies throughout the region, ranging from arid in deserts to humid, particularly in West Africa.

The CLIMEX software supports ecological research by incorporating modelling of the potential distributions of species under various climate scenarios and assumes that climate is the paramount determining factor of plant and poikilothermal animal distributions. The model allows the determination of geographically relevant climatic parameters describing the responses of an organism to climate and imposes limitations to the geographical distribution of a species and determines seasonal phenology and abundance. The Annual Growth Index (GIA) represents the species growth potential in the favourable season, while the impact of population reduction during an unfavourable season is established by the cold, hot, wet and dry Stress Indices and their interactions. The Ecoclimatic Index (EI), the product of the GIA and Stress Indices, rates the level of suitability for occupation of a particular location or year for a species. The EI is an annual average index, derived from weekly data of the growth and Stress Indices of suitability levels of climatic factors, denoted by a value on the scale 0 to 100 . A species can establish when $\mathrm{EI}>0$.

CLIMEX categorised areas according to high suitability, suitability, marginal suitability and unsuitability based on other studies using CLIMEX (Paterson et al. 2017). In the present study, temperature index, moisture index, cold stress, heat stress, dry stress, wet stress and degree-day threshold were fitted according to global distribution data, iteratively adjusted to achieve satisfactory agreement between known and projected distributions of the species globally. Detailed justification of these parameters and values used in oil palm modelling are provided in Paterson et al. (2015, 2017) respectively.

The maps were magnified on a computer screen to focus on these regions specifically using the magnification facility. The percentages of highly suitable and suitable climates were 
Fig. 1 Maps of suitable climate in African countries with highly suitable (red) and suitable (yellow) climate for grown oil palm (Paterson et al. 2017). The blue and no colour represent marginal and unsuitable climates respectively. The green spots represent existing oil palm occurrence. a Current time, b 2050 by MIROC-H, c 2100 by CSIROMk 3.0 a Current time

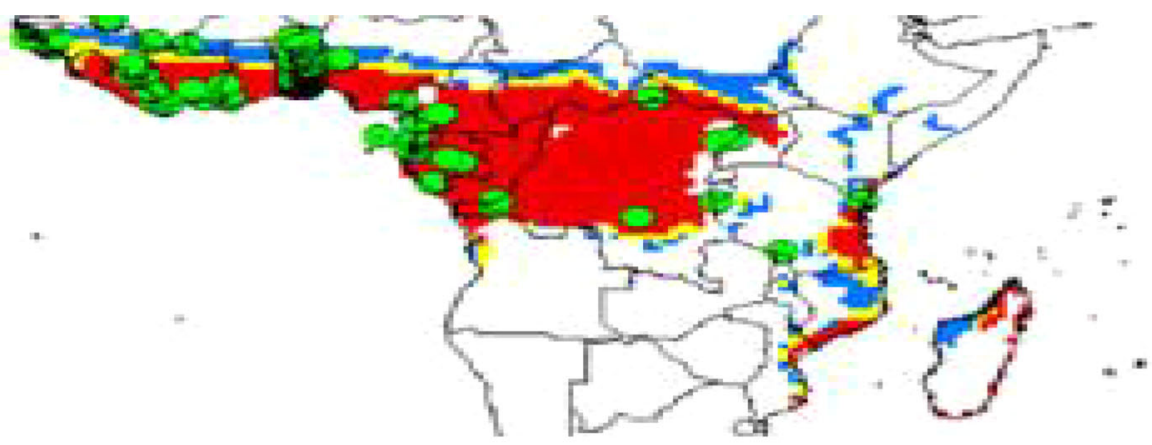

b 2050 by MIROC-H

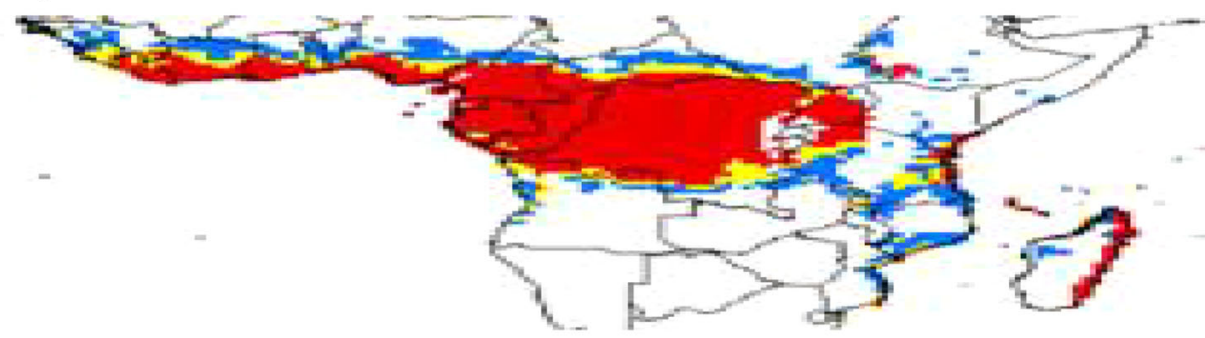

c 2100 by CSIRO-Mk 3.0

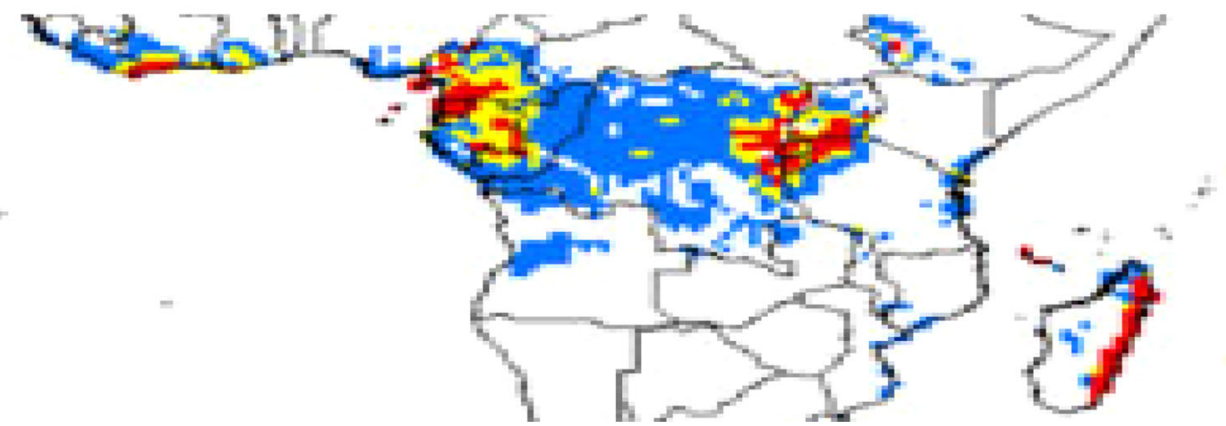

determined by assessing visually the areas of red and yellow in each map, where red represented highly suitable climate and yellow the suitable climate for growing OP. These two sets of suitabilities were combined to form the combined suitable climate (CSC) parameter.

The oil palm distribution was determined by the Global Biodiversity Information Facility (GBIF) (http://www.gbif. org/, accessed 9 November 2015) and additional literature on the species in CAB Direct (http://www.cabdirect.org/ web/about.html, accessed October 2015), and formed the basis for the collection of data on the E. guineensis distribution in (Paterson et al. 2017) with 2465 records utilized in fitting the parameters. The CLIMEX in conjunction with the A2 Special Report on Emissions Scenarios (SRES) scenario, a mechanistic niche model using the CLIMEX software supports ecological research incorporating the modelling of species' potential distributions under differing climate scenarios and assumes that climate is the paramount determining factor of plant and poikilothermal animal distributions.
CLIMEX output categorized areas according to highly suitable climate, suitable climate, marginal climate and unsuitable climate based on other studies through CLIMEX. The determinations of the mortality of oil palm are determined from especially marginal and unsuitable climate increases. Countries within the oil palm belt are indicated in Corley and Tinker (2015). CSC data were plotted against each country which was represented by its most western longitude considered (Table 1).

\section{Results and discussion}

Maps of the suitability for oil palm growth are shown in Fig. 1. In general, the highly suitable climate category (red) was the most prevalent by far for current time and 2050. However, marginal climate (blue) was dominant by 2100 . The average CSC in current time for all 17 countries studied was $53.5 \%$. Figure 2 demonstrates a large reduction in CSC in current time 
Table 1 Percentage combined suitable climate (CSC) for growing oil palm in the African countries discussed in the current paper. The CSC data for 2050 and 2100 are an average of the MIROC-H and CSIRO-
Mk3.0 maps in Paterson et al. (2017) for each year. The longitude refers to the most western part of the country. The figures in brackets represent the percentage increases over current time in 2050 and 2100

\begin{tabular}{llllllll}
\hline Country & Longitude & $\begin{array}{l}\text { CSC } \\
\text { Current time }\end{array}$ & CSC 2050 & $\begin{array}{l}\text { CSC 2050 } \\
\text { minus CSC } \\
\text { current time }\end{array}$ & CSC 2100 & $\begin{array}{l}\text { CSC 2100 } \\
\text { minus CSC 2050 }\end{array}$ \\
\hline Sierra Leon & -14 & 100 & 69 & -31 & 0 & -69 & Comments \\
Liberia & -12 & 100 & 92 & -8 & 1 & -91 & Large decreases \\
Ivory Coast & -8 & 95 & 60 & -35 & 7 & -53 & Large decreases \\
Ghana & -4 & 60 & 31 & -29 & 6 & -25 & Large decreases \\
Nigeria & 3 & 40 & 15 & -25 & 3 & -12 & Large decreases \\
Cameroon & 8 & 65 & 61 & -4 & $62(2)$ & 1 & Almost no effect \\
Gabon & 9 & 100 & 99 & -1 & 68 & -31 & Decreases \\
Republic of Congo & 11 & 100 & 100 & 0 & 36 & -64 & Decreases \\
Angola & 12 & 3 & $6(100)$ & 3 & $8(167)$ & 2 & Large increases \\
Democratic Republic of Congo & 13 & 83 & 80 & -3 & 62 & -18 & Decreases \\
Central African Republic & 15 & 63 & 35 & -28 & 2 & -33 & Large decreases \\
Uganda & 28 & 31 & $91(193)$ & 60 & $45(45)$ & -46 & Large increases \\
Tanzania & 29 & 18 & $19(5)$ & 1 & 14 & -5 & Almost no effect \\
Mozambique & 38 & 38 & 1 & -37 & 0 & -1 & Large decreases \\
Ethiopia & 33 & 2 & $5(150)$ & 3 & $5(150)$ & 0 & -4
\end{tabular}

in the 17 countries represented by longitudes $-14^{\circ}$ to $44^{\circ}$ from Sierra Leon in the west to Madagascar in the east of Africa. Ten of these countries, from Sierra Leon to DRC, are within the oil palm belt and 7 countries, from the Central African Republic (CAR) to Madagascar, are not in the oil palm belt being situated further east. Table 1 provides the assigned longitude to each of these countries.

Very high levels of CSC of more than $50 \%$ were obtained for Sierra Leon, Liberia, Ivory Coast, Ghana, Cameroon, Gabon, Republic of Congo (RC), Democratic Republic of Congo (DRC) and CAR. Only CAR is outside the oil palm belt. Nigeria had a CSC of $40 \%$ and has the most developed oil palm industry in Africa.

The average CSC for all countries for 2050 was $45.8 \%$ which is $7.7 \%$ lower than current time. The countries with higher than 50\% CSC were Sierra Leon, Liberia, Ivory Coast, Cameroon, Gabon, RC, DRC and Uganda and the counties with increases in CSC were Angola, Uganda, Ethiopia and Madagascar. Only Angola is within the oil palm belt. The 2050 data (Fig. 2b) indicated that the west to east trend of CSC in Africa was at a lower level than for current time (Fig. 2). However, the slope of the trend line indicated that the change in climate from current time to 2050 reduced the decrease in CSC from west to east Africa. This indicated an ameliorating effect of longitude on the reduction in suitable climate from west to east Africa from changing climate by 2050 compared with current time.
The large increase in CSC for Uganda (Table 1, Fig. 2b) is remarkable and indicates how climate change could increase the suitability of climate for growing oil palm. Uganda may have a viable oil palm industry from this point of view although other factors will affect this possibility. For example, severe land degradation, deforestation, soil erosion and unsustainable groundwater extractions have taken place in Uganda, driven by demand for additional agricultural land due to rapid human population increases, causing the loss of forest and woodland habitats and putting additional pressure on local threatened palms (Blach-Overgaard et al. 2015).

The difference between the CSC for 2050 and current time are presented in Fig. 2c indicating the effect of longitude on this difference. From west to east Africa, Sierra Leon, Ivory Coast, Ghana, Nigeria, CAR and Mozambique had the greatest reductions in CSC of -20 to $-40 \%$ (Fig. 2c; Table 1). There was a cluster of five counties at similar longitude of ca. 8-13 which (a) represented Cameroon, Gabon, RC, Angola and DRC, and (b) demonstrated little change in CSC. However, of the greatest interest is the increasing trend for the difference in CSC from west to east Africa.

The data for 2100 are shown in Fig. 3 and Table 1 which indicate that the average CSC for 2100 was $19.8 \%$, much lower than the figure for 2050. There was little indication of a trend in CSC because the slope of the trend line was approximately zero. Counties with more than $50 \%$ CSC were Cameroon, Gambon and DRC which were all in the oil palm 
Fig. 2 a Percentage combined suitable climate (CSC) for current time for the 17 countries discussed in the present paper and represented by the longitude of the country as listed in Table 1. Sierra Leon is the extreme west at $-14^{\circ}$ and Madagascar is the extreme east at $44^{\circ}$. The trend line is also presented. b Percentage combined suitable climate (CSC) for 2050 for the 17 countries discussed in the present paper and represented by the longitude of the country as listed in Table 1. Sierra Leon is the extreme west at $-14^{\circ}$ and Madagascar is the extreme east at $44^{\circ}$. The trend line is also presented. c Difference between combined suitable climate (CSC) for 2050 minus current time for the 17 countries discussed in the present paper and represented by the longitude of the country as listed in Table 1. Sierra Leon is the extreme west at $-14^{\circ}$ and Madagascar is the extreme east at $44^{\circ}$. The trend line is also presented
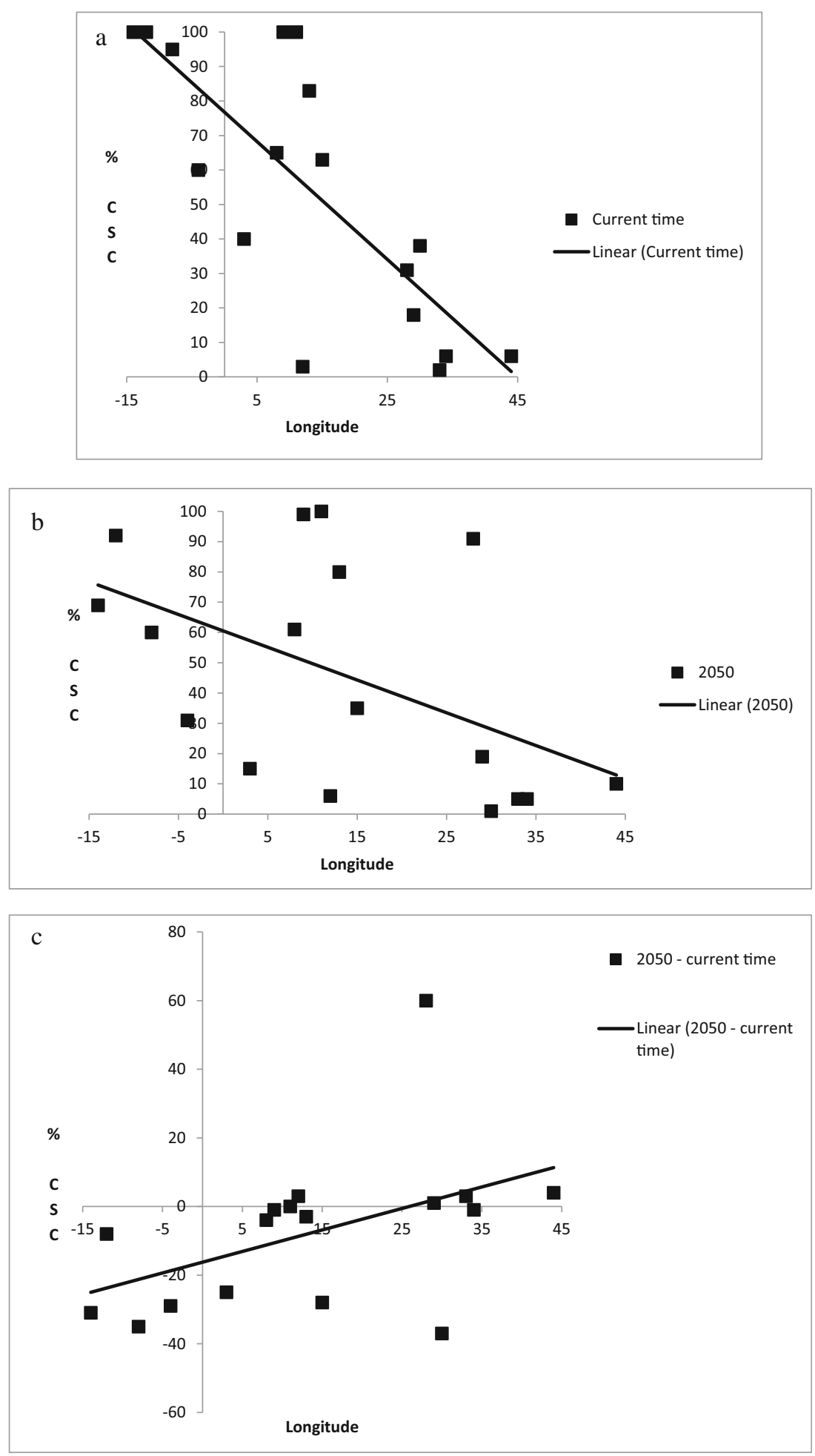

belt and had similar longitudes. These countries could support an oil palm industry climatically even by 2100 if other relevant factors are also conducive. The Republic of Congo (36\%) and Uganda (45\%) had moderately high levels CSC and could still support an industry, given that Nigeria is the largest current producer with a CSC of $40 \%$ in current time.
Figure $3 \mathrm{~b}$ illustrates the difference between the CSC in 2100 minus 2050 and indicates the strong influence of longitude in reducing the negative effect of climate on CSC in a similar manner described for 2050 minus current time. Small increased values were observed from Cameroon, Angola and Madagascar and no effect was observed for Ethiopia over 
Fig. 3 a Percentage combined suitable climate (CSC) for 2100 for the 17 countries discussed in the present paper and represented by the longitude of the country as listed in Table 1. Sierra Leon is the extreme west at $-14^{\circ}$ and Madagascar is the extreme east at $44^{\circ}$. The trend line is also presented. b Difference between combined suitable climate (CSC) for 2100 minus 2050 for the 17 countries discussed in the present paper and represented by the longitude of the country as listed in Table 1. Sierra Leon is the extreme west at $-14^{\circ}$ and Madagascar is the extreme east at $44^{\circ}$. The trend line is also presented
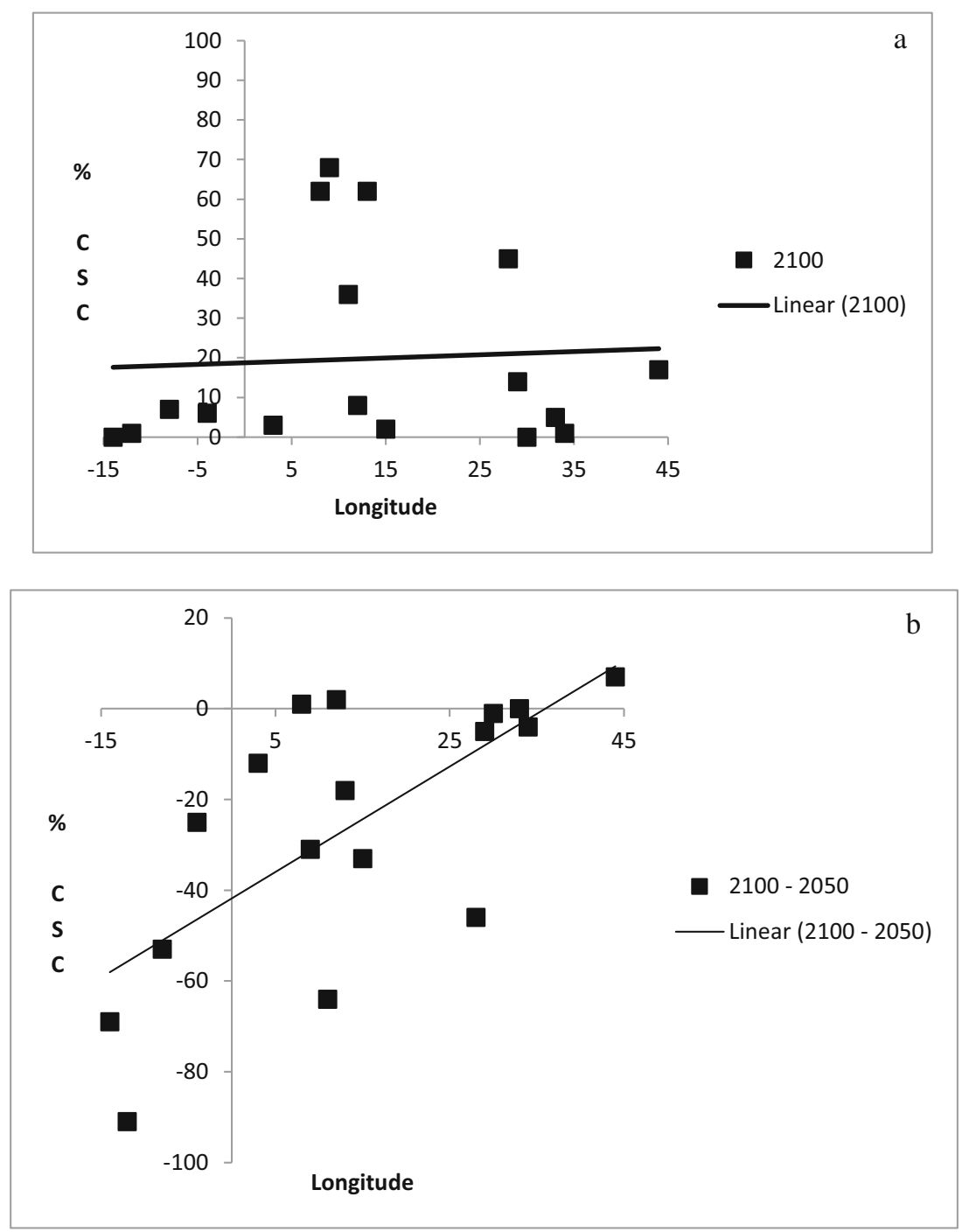

2050 values (Table 1, Fig. 3b). The industry in these countries could survive climate change but would not compensate for the general reduction in CSC elsewhere. Nevertheless, the trend supports the contention of an increasing longitudinal trend for reducing the negative effect of climate change on CSC.

The levels of CSC increased 6,10 and $17 \%$ in current time, 2050 and 2100 respectively for Madagascar which are large increases and may help support the oil palm industry in that country. Tanzania and Cameroon demonstrated little or no effect from climate change and the oil palm industry might develop in these counties, at least from the point of view of suitable climate (Table 1).

Increased CSC would be anticipated for countries in the oil palm belt (Corley and Tinker 2015) such as the countries from Sierra Leon to DRC, compared to those that are located further east and may present distinctly different patterns of climate suitability to regions not in the oil palm belt. Figure 4 indicates the difference in CSC between the data for 2050 and that for current time for the oil palm belt countries. However, an increase in the differences in CSC from west to east Africa was apparent in a similar manner to when all countries were considered (Fig. 2c). An increasing trend was also indicated for the 2100 minus the 2050 data from west to east Africa (Fig. 4b) which was greater than for 2050 minus current time differences (Fig. 4). The longitudinal effect for all countries considered herein also applies to those only in the oil palm belt. Hence, there is good reason to predict that refuges for oil palm will exist towards the east of Africa in the oil palm belt because the general conditions are favourable in current time. Blach-Overgaard et al. (2015) suggested the use of assisted colonization to help species track climate change and the results presented herein indicate utilising the more easterly countries may be appropriate for this purpose. The trend for the change in difference in CSC for non-oil palm belt countries between (a) current time and 2050 (Fig. 5) and (b) 2050 and 2100 (Fig. 5b) indicated it was also positive from west to east Africa. Hence, the trends are increasingly positive 
Fig. 4 a Difference between combined suitable climate (CSC) for 2050 minus current time for the 10 countries of the oil palm belt and represented by the longitude of the country as listed in Table 1. Sierra Leon is the extreme west at $-14^{\circ}$ and the Democratic Republic of Congo is the east at $13^{\circ}$. The trend line is also presented. b Difference between combined suitable climate (CSC) for 2100 minus 2050 for the 10 countries of the oil palm belt and represented by the longitude of the country as listed in Table 1. Sierra Leon is the extreme west at $-14^{\circ}$ and the Democratic Republic of Congo is the east at $13^{\circ}$. The trend line is also presented
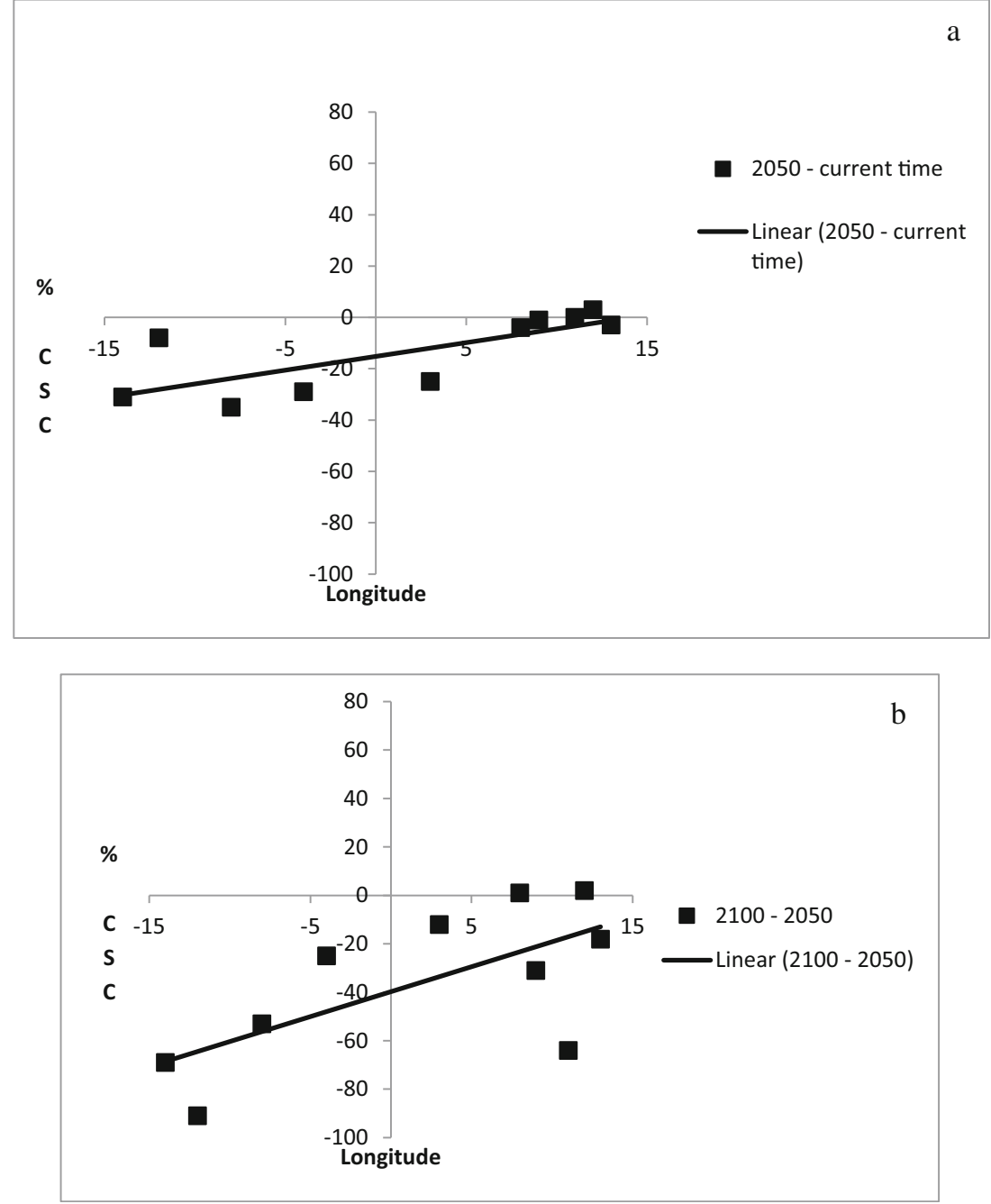

differences from west to east Africa for the oil palm belt and non-oil palm belt countries from climate change.

The oil palm belt was considered more detail herein because all the conditions currently exist for high levels of oil palm growth by implication — not just those related to a suitable climate. For example, suitable soil and slope of cultivation are likely to be suitable as are socioeconomic factors. Hence, if there is an improvement in suitable climate, then the other conditions necessary for oil palm growth already exist. This is not necessarily the case for the other countries outside the oil palm belt if the climate improves.

Climate has an important role in defining the range limits of oil palm distribution by exerting eco-physiological constraints (Paterson et al. 2017). However, factors such as soil properties and biotic interactions may prevent the plant from colonizing sites that are otherwise suitable. Changes in climate will have broad-scale impacts on the distribution of oil palm. Changes in cold, heat and dry stresses were largely responsible for the changes in climatic suitability for oil palm cultivation while wet stress was unimportant in Paterson et al. (2017) hence extending the range of parameters from temperature alone. A negative and significant relationship was found between annual average temperature and sea level rise and oil palm production in Malaysia (Sarkar et al. 2020) who also stated that temperature rises of 1 to $4{ }^{\circ} \mathrm{C}$ can cause the production of oil palm to decrease by 10 to $41 \%$.

These data indicate how oil palm could survive climate change by displacement to more suitable refuges in the east of Africa. Latitudinal refuges may not be accessible in the tropics as mentioned above (Wright et al. 2009). Also, this trend may assist species colonization by tracking beneficial climate changes and establishing these refugees towards the east in the oil palm belt such as DRC over Sierra Leon for example. Countries such as Uganda or Tanzania being particularly suitable outside the oil palm belt. Furthermore, oil palm may be a useful marker species that may indicate how other palms could adapt to changes in climate, especially because oil palm grows in rainforest and open plane, unlike most palms which normally can grow only in one location or the other (Blach-Overgaard et al. 2015). 
Fig. 5 a Difference between combined suitable climate (CSC) for 2050 minus current time for the 7 countries not in the oil palm belt and represented by the longitude of the country as listed in Table 1. Central African Republic is the extreme west at $15^{\circ}$ and Madagascar is the extreme east at $44^{\circ}$. The trend line is also presented. b Difference between combined suitable climate (CSC) for 2100 minus 2050 for the 7 countries not in the oil palm belt and represented by the longitude of the country as listed in Table 1. Central African Republic is the extreme west at $15^{\circ}$ and Madagascar is the extreme east at $44^{\circ}$. The trend line is also presented
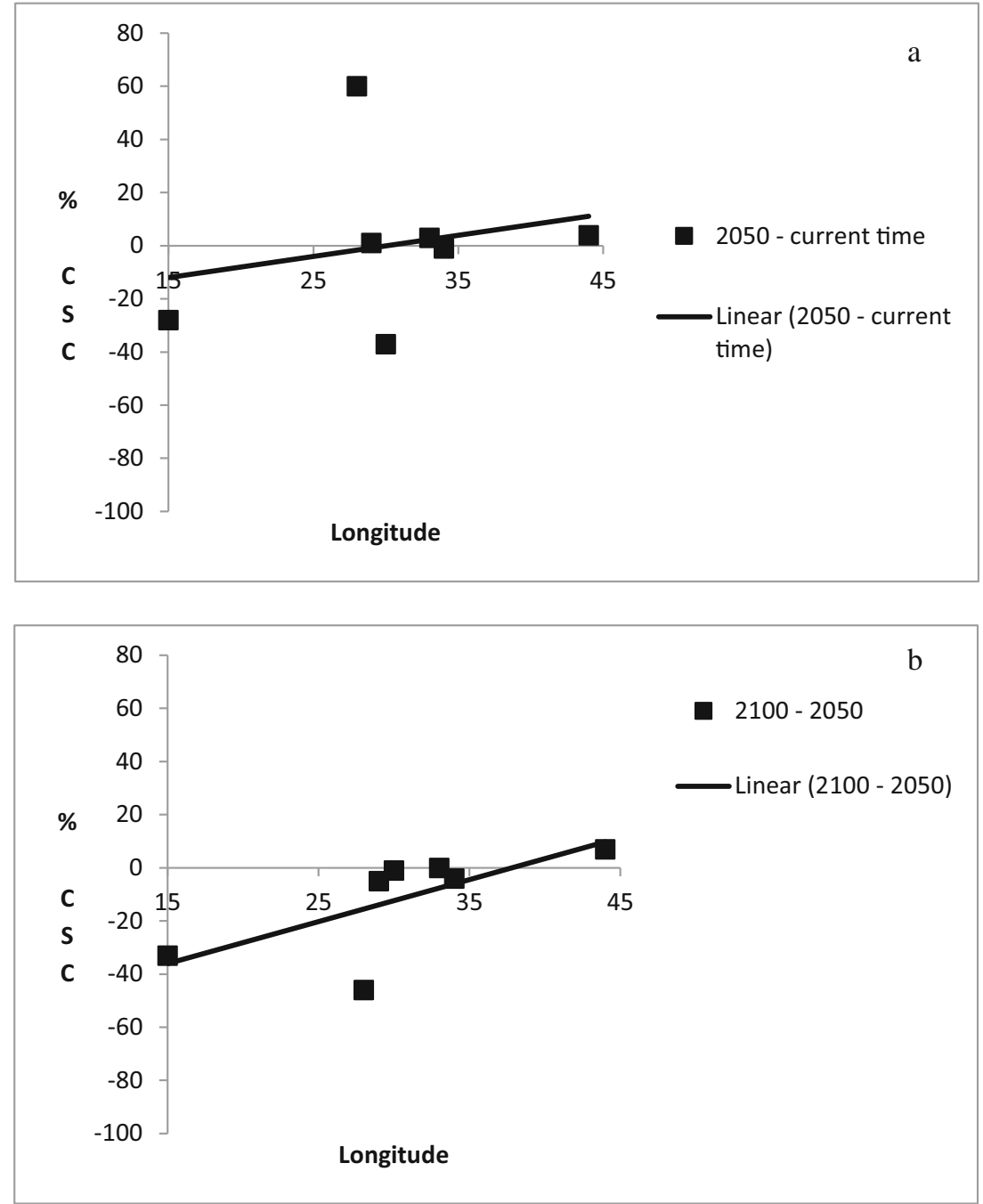

These results presented herein are particularly important because there are few data on the effect of climate change on (a) species in the tropics, and (b) longitudinal effects. Also, the data took into account temperature and moisturerelated parameters (Paterson et al. 2017) and not just temperature, which is what often occurs in climate studies (see the 'Introduction' section).

There was cold stress associated with the eastern African countries considered herein, particularly in Ethiopia, and Kenya in 2050. Heat and dry stresses were particularly associated with areas north of the tropics in Africa by 2050 in Paterson et al. (2017) and may be the reason for fewer refuges for oil palm to the north of the African tropics. Regions south of the tropics in Africa would appear to be affected by cold stress and this may reduce refuges in this direction. There was less evidence of stress factors impinging longitudinally in 2050, reinforcing the trend reported in the present paper. Hot stress pervades the tropics from the north of Africa by 2100 especially to the west of the African oil palm belt. This may be a reason for the large amount of reduced
CSC reported herein for 2100. Cold stress disappeared largely towards the south of Africa with dry stress moving even further south. Refuges may appear further south in Africa by 2100. Correlating these stresses with climate suitability is not absolute for, inter alia, complications from (a) the length of the growing season, (b) vernalisation and (c) the fact that other stresses can have an impact e.g. cold-dry, hot-dry, cold-wet and hot-wet. Wright et al. (2009) indicate that distances to cool refuges are particularly large close to the oil palm belt and particularly in the most western countries, close to Cameroon and DRC. Eastern countries such as south Sudan, Uganda and western Tanzania are much closer to cool refuges. Hence, oil palms could spread east with climate change in Africa, especially given the large distances to refuges in the west of the oil palm belt, and with little prospects of poleward movement.

It is critical to understand the effects of climate change on natural systems to predict or mitigate consequent changes in diversity and ecosystem function (Feeley et al. 2017). Anthropogenic climate change is a global phenomenon that 
has a potential impact on all species in all ecosystems. However, large-scale conversion of tropical forest to oil palm plantations has detrimental effects on biodiversity. Fitzherbert et al. (2008) determined that oil palm plantations support many fewer species than forests and some other tree crops: habitat fragmentation and increased pollution occur, including greenhouse gas emissions. Oil palm cultivation affects climate by increasing greenhouse gas emission and consequently climate change (Paterson and Lima 2018). Koh and Wilcove (2008) suggested that oil palm expansion occurs at the expense of forests, which may result in biodiversity loss. Dislich et al. (2017) determined 11 of 14 ecosystem functions decreased in levels of function by the introduction of oil palm plantations. Hence, countries which experience less severe change in climate, or a positive effect from climate change, cannot develop plantations at the expense of the environment, whether or not climate change improves oil palm growth.

The development of resistant oil palm cultivars to climate change, or environmental stress, may overcome the less favourable growth conditions imposed by climate change (Rival 2017). Furthermore, Paterson and Lima (2018) described some key areas of research and development which will reduce the effect of oil palm cultivation on climate change and the effect of climate change on oil palm agronomy. These areas included (a) inter-planting leguminous crops to increase nitrogen in the soil; (b) using empty oil palm bunches to enhance soil; (c) adding earthworms to improve soil; (d) employing arbuscular mycorrhizal fungi and (e) biochar to assist nutrition of oil palm. However, the most effective manner of addressing climate change is to adhere to the policies devised at the recent climate meeting in Spain (COP25), by reducing greenhouse gasses and keeping temperature rise to more manageable levels (file:///C:/Users/Russell/Downloads/ cp2019_L10E.pdf). Conservation scientists, managers and environmental policymakers need to adapt their guidelines and policies accordingly (Brooke 2008) to mitigate the impact of climate change.

\section{Conclusions}

Useful information relating to future climate effects on oil palm has been obtained from suitable climate maps using the CLIMEX model for tropical Africa. This is the first time that the data has been employed in this manner. A distinctly increasing trend from west to east in Africa was determined in the change in suitable climate from the current time until 2050. This indicated an ameliorating effect of longitude on the reduction in suitable climate from west to east Africa. There was a similar trend for 2050 until 2100 . The trends were increasingly positive from west to east Africa for the oil palm belt and non-oil palm belt countries from climate change. Refuges may be more likely for oil palm in the east of this region as climate change progresses. The information will be useful in the understanding of the future survival of palms in general and for plantation managers, environmentalists and governments. The effect on the environment of developing plantations in novel regions must be of prime concern. Finally, increased resources are required, in general, to reduce climate change through international cooperation.

Acknowledgements The author is grateful for the IOI Professorial Chair at University Putra Malaysia in 2018-2019.

Authors' contributions Dr. Paterson is sole author.

\section{Compliance with ethical standards}

Conflict of interest The author declares there are no conflicts of interest.

Ethical approval Not applicable.

Consent to participate Not applicable.

Consent to publish Not applicable.

\section{References}

Abila N (2010) Biofuels adoption in Nigeria: a preliminary review of feedstock and fuel productionpotentials. Management of Environmental Quality: An International Journal 21:785-795. https://doi.org/10.1108/14777831011077646

Arrieta F, Teixeira F, Yanez E, Lora E, Castillo E (2007) Cogeneration potential in the Columbian palm oil industry: three case studies. Biomass Bioenergy 31:503-511. https://doi.org/10.1016/j. biombioe.2007.01.016

Basiron Y (2007) Palm oil production through sustainable plantations. Eur J Lipid Sci Technol 109:289-295. https://doi.org/10.1002/ejlt. 200600223

Bellard C, Bertelsmeier C, Leadley P, Thuiller W, Courchamp F (2012) Impacts of climate change on the future of biodiversity. Ecol Lett 15: 365-377. https://doi.org/10.1111/j.1461-0248.2011.01736.x

Blach-Overgaard A, Balslev H, Dransfield J, Normand S, Svenning J (2015) Global-change vulnerability of a key plant resource, the African palms. Sci Rep 5:1-10. https://doi.org/10.1038/srep12611

Brooke C (2008) Conservation and adaptation to climate change. Conserv Biol 22:1471-1476. https://doi.org/10.1111/j.1523-1739. 2008.01031.x

Cho SJ, Mccarl BA (2017) Climate change influences on crop mix shifts in the United States. Scientific Reports:1-6. https://doi.org/10.1038/ srep40845

Corley RHV, Tinker PB (2015) The oil palm. Wiley Blackwell, Chichester

Cosiaux A, Gardiner LM, Stau FW, Bachman SP, Sonké B, Baker WJ, Couvreur TLP (2018) Low extinction risk for an important plant resource : conservation assessments of continental African palms ( Arecaceae / Palmae ). Biol Conserv: 221, 323-333. https://doi.org/ 10.1016/j.biocon.2018.02.025

Dislich C, Keyel AC, Salecker J, Kisel Y, Meyer KM, Auliya M et al (2017) A review of the ecosystem functions in oil palm plantations, using forests as a reference system. Biol Rev Camb Philos Soc 49: $1539-1569$ 
Feeley KJ, Stroud JT, Perez TM (2017) Most ‘ global ' reviews of species ' responses to climate change are not truly global. Divers Distrib 23: 231-234. https://doi.org/10.1111/ddi.12517

Fei S, Desprez JM, Potter KM, Jo I, Knott JA, Oswalt CM (2017) Divergence of species responses to climate change. Sci Adv 3: e1603055

Fitzherbert EB, Struebig MJ, Morel A, Danielsen F, Brühl CA, Donald PF, Phalan B (2008) How will oil palm expansion affect biodiversity? Trends Ecol Evol 23:538-545. https://doi.org/10.1016/j.tree. 2008.06.012

Ghini R, Bettiol W, Hamada E (2011) Diseases in tropical and plantation crops as affected by climate changes: current knowledge and perspectives. Plant Pathol 60:122-132. https://doi.org/10.1111/j.13653059.2010.02403.x

Kadandale S, Smith R (2019) The palm oil industry and noncommunicable diseases. Bull World Health Organ 97:118-128

Koh LP, Wilcove DS (2008) Is oil palm agriculture really destroying tropical biodiversity? Conserv Lett 1:60-64

Lena BD, Farinelli D, Palliotti A, Poni S, Theodore M, Tombesi S, Di B et al (2018) Impact of climate change on the possible expansion of almond cultivation area pole-ward : a case study of Abruzzo, Italy. J Hortic Sci Biotechnol 93:209-215. https://doi.org/10.1080/ 14620316.2017.1357433

Lenoir J, Svenning J (2015) Climate-related range shifts - a global multidimensional synthesis and new research directions. Ecography 38: 15-28. https://doi.org/10.1111/ecog.00967

Lobell DB, Field CB, Cahill KN, Bonfils C (2006) Impacts of future climate change on California perennial crop yields: model projections with climate and crop uncertainties. Agric For Meteorol 141: 208-218. https://doi.org/10.1016/j.agrformet.2006.10.006

Marlier ME, Defries R, Pennington D, Nelson E, Ordway EM, Lewis J, Koplitz et al. (2014) Future fire emissions associated with projected land use change in Sumatra. Glob Chang Biol 21: 345-362

Miller AE, Wilson TL, Sherriff RL, Walton J (2017) Warming drives a front of white spruce establishment near western treeline, Alaska. Global Climate Change 23:5509-5522. https://doi.org/10.1111/gcb. 13814

Ohimain EI, Izah SC (2014) Energy self-sufficiency of smallholder oil palm processing in Nigeria. Renew Energy 63:426-431. https://doi. org/10.1016/j.renene.2013.10.007

Ommelna BG, Jennifer AN, Chong K (2012) The potential of chitosan in suppressing Ganoderma boninense infection in oil-palm seedlings. J Sustain Sci Manag 7:186-192

Parmesan C (2006) Ecological and evolutionary responses to recent climate change. Annu Rev Ecol Evol Syst 37:637-669. https://doi.org/ 10.1146/annurev.ecolsys.37.091305.110100

Paterson RRM (2020) Oil palm survival under climate change in Kalimantan and alternative SE Asian palm oil countries with future basal stem rot assessments. For Pathol 50:e12604

Paterson RRM, Lima N (2018) Climate change affecting oil palm agronomy, and oil palm cultivation increasing climate change, require amelioration. Ecology and Evolution 8:452-461
Paterson RRM, Kumar L, Taylor S, Lima N (2015) Future climate effects on suitability for growth of oil palms in Malaysia and Indonesia. Sci Rep 5:14457. https://doi.org/10.1038/srep14457

Paterson RRM, Kumar L, Shabani F, Lima N (2017) World climate suitability projections to 2050 and 2100 for growing oil palm. J Agric Sci 155:689-702. https://doi.org/10.1017/ S0021859616000605

Ramirez-Cabral NYZ, Kumar L, Shabani F (2017) Global alterations in areas of suitability for maize production from climate change and using a mechanistic species distribution model (CLIMEX). Sci Rep 1-13. https://doi.org/10.1038/s41598-017-05804-0, 7

Rival A (2017) Breeding the oil palm (Elaeis guineensis Jacq.) for climate change. Ocl 24:D107. https://doi.org/10.1051/ocl/2017001

Rosenzweig C, Karoly D, Vicarelli M, Neofotis P, Wu Q, Casassa G, Menzel A, Root TL, Estrella N, Seguin B, Tryjanowski P, Liu C, Rawlins S, Imeson A (2008) Attributing physical and biological impacts to anthropogenic climate change. Nature 453:353-357. https://doi.org/10.1038/nature06937

Sarkar MSK, Begum RA, Pereira JJ (2020) Impacts of climate change on oil palm production in Malaysia. Environ Sci Pollut Res 27:9760 9770

Shabani F, Kumar L, Esmaeili A (2014) Future distributions of Fusarium oxysporum f. spp. in European, Middle Eastern and North African agricultural regions under climate change. Agriculture. Ecosystems and Environment 197:96-105. https://doi.org/10.1016/j.agee.2014. 08.005

Sinervo B, Méndez-de-la-Cruz F, Miles DB, Heulin B, Bastiaans E, Cruz MVS, Lara-Resendiz R et al (2010) Erosion of lizard diversity by climate change and altered thermal niches. Science 328:894-899. https://doi.org/10.1126/science.1184695

Sittaro F, Paquette A, Messier C, Nock CA (2017) Tree range expansion in eastern North America fails to keep pace with climate warming at northern range limits. Glob Chang Biol 23:3292-3301. https://doi. org/10.1111/gcb.13622

Thackeray SJ, Sparks TH, Frederiksen M, Burthe S, Bacon PJ, Bell JR, Botham MS et al (2010) Trophic level asynchrony in rates of phenological change for marine, freshwater and terrestrial environments. Glob Chang Biol 16:3304-3313. https://doi.org/10.1111/j. 1365-2486.2010.02165.x

Urban M (2015) Accelerating extinction risk from climate change. Science:571 348-571 573

Villela AA, Jaccoud DB, Rosa LP, Freitas MV (2014) Status and prospects of oil palm in the Brazilian Amazon. Biomass Bioenergy 67: 270-278. https://doi.org/10.1016/j.biombioe.2014.05.005

Wright SJ, Muller-Landau HC, Schipper JAN (2009) The future of tropical species on a warmer planet. Conserv Biol 23:1418-1426. https://doi.org/10.1111/j.1523-1739.2009.01337.x

Publisher's note Springer Nature remains neutral with regard to jurisdictional claims in published maps and institutional affiliations. 